\title{
Aula Magna
}

\section{Una '(in)cultura única' de invisibilización de las mujeres en la Ciencia y la Filosofía}

\author{
Concha Roldán Panadero \\ Directora del Instituto de Filosofía del Consejo Superior de Investigaciones Científicas (CSIC), Madrid, \\ España; concharoldancsic@gmail.com
}

La famosa conferencia pronunciada por Charles P. Snow en Cambrigde en 1959 bajo el título “Las dos culturas y la revolución científica" 1, contribuyó a dar carta de naturaleza al hiato entre las ciencias experimentales y las humanidades, en detrimento de estas últimas. Snow sostenía que había una total incomunicación entre las dos comunidades, la científica y la humanista, y, aunque se refería en su discurso fundamentalmente a la Literatura, sin duda la Filosofía perdió también en esta batalla su égida histórica como Ciencia Primera o Ciencia de las Ciencias, acusada de no haber sabido entender la revolución tecnológica por aferrarse a unos sistemas de valores anticuados. A dicho discurso respondió en el Hall del Downing Colleage de Cambridge F. R. Leavis originándose la polémica que ha llegado a nuestros días y que, sin embargo, ya tenía una larga prehistoria en una polémica anterior mantenida en Inglaterra por T. H. Huxley y Matthew Arnold ${ }^{2}$ y que hacía pie en la defensa positivista de un progreso científico, que -como bien han puesto de manifiesto los filósofos desde Leibniz a Hannah Arendt- hacía caso omiso del progreso moral de la humanidad. Una de las consecuencias fundamentales de esta polarización ha sido la paulatina reducción de los sistemas de estudios de enseñanza secundaria de materias humanísticas, a favor de las ciencias "duras", así como el detrimento en los ámbitos de la evaluación de la investigación de las aportaciones de estas últimas.

Ahora bien, algo en lo que Ciencia y Humanidades fueron siempre de la mano fue en la constitución de una única (in)cultura de invisibilización de las mujeres en sus historias oficiales. Como contrapunto, durante las últimas décadas, algunos esfuerzos feministas han puesto sobradamente de manifiesto la ausencia de las mujeres en las historias de la ciencia, en las historias del pensamiento o en las historias "oficiales" en general, de las que las historias de la filosofía no han sido una excepción. Por doquier han florecido numerosas historias de mujeres científicas y filósofas que no sólo han tenido el valor de denunciar la exclusión de las mujeres de la vida pública -de la que también forman parte las publicaciones, como su nombre indica-, por el mero hecho de ser mujeres, sino también de paliar con nuevos datos el vacío de tradición genérica, la ausencia de modelos, ante el que se encontraban las mujeres de nuestra generación. Pues no sólo se nos había hurtado siglo tras siglo el saber a las mujeres, sino que también se nos privó de referentes en el pasado, al excluir de las "historias" a aquellas que habían osado robar prometeicamente el fuego que, supuestamente, los dioses habían entregado a los varones para su custodia... Así, las mujeres científicas o filósofas fueron toleradas, e incluso admiradas, por sus coetáneos como excepciones (que no engendraban peligro si no constituían norma), cuando no calificadas de "milagro de la naturaleza" o de "espíritus masculinos en cuerpos femeninos", a quienes sólo les faltaba la barba para restablecer el equilibrio y armonía naturales 3, y cuyos "desvaríos intelectuales" no habían de tenerse muy en cuenta. Por eso

1 Cf. Ch. P. Snow The two cultures, New York, Cambrigde University Press, 1959

2 Cf. http://www.terceracultura.net/tc/el-otro-choque-de-culturas/

3 En este sentido se refirió Kant - conocido como el "padre de la ética moderna" - a Madame de Châtelet; cf. Observaciones sobre el sentimiento de lo bello y lo sublime: “a una mujer con la cabeza llena de griego, como la señora Dacier, o que sostiene sobre mecánica discusiones fundamentales, como la marquesa de Châtelet, parece que no le hace falta más que una buena barba" (AA II, 229). Cf. al respecto C. Roldán, "Ni virtuosas ni ciudadanas: 
denunciaba Virginia Woolf: "suponiendo que Newton hubiera sido mujer, los documentos históricos se hubieran olvidado de recoger en sus páginas la ley de gravitación universal" " ". Las razones de los olvidos de la razón" -como ha escrito Celia Amorós- "se sustentan en una concepción patriarcal de la historia" 5 , de forma que sólo fragmentariamente (y tras ardua indagación bibliográfica) podemos tener conocimiento de que en los orígenes de la modernidad existieron unas pensadoras llamadas Anna María van Schurman, Anne Finch Conway, Marie Winkelmann von Kirch o Emilie de Châtelet, que tuvieron una extraordinaria producción literaria, filosófica o científica, de la que sólo una pequeña muestra ha llegado a nuestras manos, pues el resto desapareció como los restos de un naufragio, engullidos por el mar del olvido.

Todas estas recuperaciones de historias de mujeres científicas y filósofas, con todo su valor, han quedado sin embargo recluidas en los ámbitos de las investigadoras feministas ${ }^{6}$, en su gueto, y no han tenido ninguna repercusión en las Historias oficiales de las Ciencias y de la Filosofía que se han ido escribiendo a finales del siglo XX o comienzos del XXI, ni han tenido trascendencia alguna en los temarios y programas de estudios de la Filosofía, ni en la enseñanza secundaria ni en la universitaria: no se ha operado, pues, una verdadera "reconstrucción" histórica, si no que las investigaciones sobre mujeres filósofas en todas las épocas han quedado relegados a una especie de repertorio de ausencias o "fe de olvidos" que, en el mejor de los casos, se presenta como un añadido a las historias de siempre y que, como sucede con las conocidas "fe de erratas", termina usándose como señalador o simplemente traspapelándose.

Tras una lucha de siglos de las mujeres por la igualdad, asistimos a un creciente protagonismo de las mujeres en la vida profesional y política occidental, pero la piedra de toque sigue siendo hasta qué punto hemos alcanzado de facto una igualdad que nadie se atreve a hurtarnos de iure en nuestra cultura, una cuestión a la que responden negativa y paradigmáticamente -de manera sangrante- los casos de violencia doméstica o que, por otro lado, no dejan de poner en entredicho las estadísticas que muestran cómo el porcentaje de mujeres va disminuyendo según ascendemos en la escala de responsabilidades hasta alcanzar el denominado "techo de cristal", que ya se ha convertido en "techo de acero". A menudo nos preguntamos tanto desde un punto de vista teórico como práctico por los logros feministas ${ }^{7}$ en sus distintas etapas, para terminar cuestionando el que hayamos llegado a alguna meta definitiva, poniendo de manifiesto, por el contrario, que en todos los países del mundo nos hallamos todavía inmersas -en mayor o menor medida- en dinámicas patriarcales y sexistas, que no podrán ser erradicadas si no nos volvemos conscientes de las rémoras históricas que componen el humus de nuestras sociedades, en torno a tres puntos clave: el acceso de las mujeres al mundo del conocimiento (educación), la obtención de derechos cívicos (ciudadanía, voto, leyes) y su participación activa en las actividades que dirigen la vida pública (cargos políticos, empresariales o académicos).

inconsistencias prácticas en la teoría de Kant", en Ideas y valores. Revista colombiana de filosofía, LXII, Suplemento 1, 2013, pp. 185-203.

${ }^{4}$ Cf. Virginia Woolf, Una habitación propia, 1929.

${ }^{5}$ Cf. Amorós, C. Tiempo de feminismo. Sobre feminismo, proyecto ilustrado y postmodernidad. Madrid, Cátedra, 1997.

${ }^{6}$ Cf. por ejemplo, A History of Women Philosophers, vol. I-III, ed. de Mary Ellen Waithe, Dordrecht, 1991; Philosophinnen Lexikon, ed. de Ursula I. Meyer y Heidemarie Bennent-Vahle, Leipzig, 1997; Klassische philosophische Texte von Frauen (hg. Von Ruth Hagengruber), München, 1998; Mujeres en la historia del pensamiento (ed. de Rosa Mª Rodríguez Magda), Anthropos, Barcelona, 1997; o los mismos tres volúmenes Teoría feminista: de la Ilustración a la globalización (ed. Celia Amorós y Ana de Miguel), Minerva ediciones, Madrid, 2005.

7 Entiendo por "feminismo" en singular, en el sentido que lo empleara Alice Jaggar (Feminist Politics and Human Nature, Totowa, NJ, p. 5), "lo común a las diversas formulaciones de la teoría feminista en su compromiso por terminar con la subordinación, marginación, discriminación /dominación-explotación, y violencia-tortura contra las mujeres". 
Desgraciadamente, en lo que respecta a la igualdad de las mujeres no nos encontramos ante un capítulo cerrado. Y como viene mostrándose en un gran número de seminarios y proyectos de investigación, de congresos y publicaciones no sólo el papel de la mujer en la ciencia y en la filosofía sigue siendo el resultado de prejuicios y posturas viciadas aprendidas -algo que no sólo actúa en detrimento de la participación femenina sino que hace que se resienta la misma ciencia en sus cimientos-, sino que esto sigue manifestándose en la violencia física y psicológica que se sigue ejerciendo contra las mujeres, pues no nos parece que pueda separarse la violencia de género, la prostitución y la trata de blancas del tema de la ausencia de las mujeres de las historias de la filosofía y de su presencia en los temarios que se enseñan en los cursos de filosofía de los Institutos de Enseñanza Secundaria, ni de los de las Universidades. En nuestras sociedades en las que todo se puede comprar o vender, en las que los estudios universitarios cuestan cada vez más, la vuelta de la repartición social de los roles clásicos de "hombres" y "mujeres" es cada vez más amenazante, como lo es la vuelta de las políticas neoconservadoras en occidente: un caldo de cultivo más que propicio para un patriarcado que vuelve con fuerzas renovadas, como ese Alien cinematográfico que aparece una y otra vez cuando ya lo creemos aniquilado, colándose viscoso y pregnante por todas las rejillas y hendiduras posibles $\mathrm{y}$, lo que es aún mucho peor, germinando dentro de nosotras/os mismas/os y destruyéndonos por dentro.

Con todo, quisiera acabar estas líneas en tono optimista, con el deseo de que los avances de las últimas décadas en aras de una verdadera interdisciplinariedad, como integración de conocimientos pertenecientes a disciplinas distintas, constituya también un acicate para la inclusión definitiva de las aportaciones de las mujeres científicas y filósofas a las historias oficiales, que también se encuentran ahora con el reto de incluir ámbitos de investigación transfronterizos, tales como la historia social, la geografía política, la sociolinguística, la epistemología histórica, los estudios feministas, los estudios culturales o la bioética. La fragmentación del saber especializado y el descrédito del conocimiento experto, sugieren la integración de diferentes perspectivas y comunidades de conocimiento, ya sean disciplinares o abiertas, sobre temas de estudio comunes, lo cual supone un reto notable para las propias ciencias y la filosofía.

Conflicto de Intereses: el autor declara no tener conflicto de intereses

(C) 2018 por los autores; Esta obra está sujeta a la licencia de Reconocimiento 4.0 Internacional de Creative Commons. Para ver una copia de esta licencia, visite http://creativecommons.org/licenses/by-nc-nd/4.0/. 